УДК $536.66+543.86$

\title{
КИНЕТИЧЕСКИЙ МЕТОД ОПРЕДЕЛЕНИЯ ВИТАМИНА Е В МАСЛАХ ЗАРОДЫШЕЙ ПШЕНИЦЫ
}

\section{(C) Н.В. Сизова}

\author{
Институт химии нефрти Сибирского отделения Российской академии наук, \\ пр. Академический, 4, Томск, 634055 (Россия), e-mail: sizovaNV@mail.ru
}

Методом микрокалориметрии определено количество витамина $E$ в маслах зародышей пшеницы, полученных разными производителями. Показано, что максимальное количество токоферолов содержится в масле зародышей пшеницы, полученном механической переработкой по щадящей технологии профессора А.Б. Вишнякова. Проанализированы восемь образцов масел зародышей пшеницы, полученных на предприятии ООО «СибТар», с 2011 по 2015 гг. в разных технологических циклах. Комплекс синергетических компонентов масла показывает высокое содержание антиоксидантов, соответствующее количеству токоферолов от 240 до 420 мг\%, что превышает справочные данные. Основное условие получения высоковитаминного масла - использование хорошего сырья, проведение процесса прессования без нагревания и использования растворителей. Показано, что содержание токоферолов для масел, полученных в разные годы, отличается до $40 \%$, в наибольшей степени это зависит от условий произрастания зерна и условий его хранения. Содержание токоферолов в одном виде масла может служить критерием качества. Так, для двух образцов исследованных масел зародышей пшеницы получены данные по содержанию витамина $E$ в три раза ниже справочных, что свидетельствует о разведении масла другими видами масел.

Ключевые слова: масло зародышей пшеницы, натуральные антиоксиданты, кинетический метод определения токоферолов.

В настоящее время качественное растительное масло является предметом функционального питания, поставщиком жирных кислот и жирорастворимых витаминов. Масло зародышей пшеницы (МЗП) содержит максимальное количество гомологов токоферола (витамина $E$ ) из всех известных природных источников, при этом в нем преобладает наиболее активная форма витамина $E$ - $\alpha$-токоферол (около $70 \%$ ) [1]. Токоферолы относятся к классу метилированных фенолов и являются главными натуральными антиоксидантами (AO), употребляемыми человеком с пищей. Увеличенное суточное потребление витамина $E$ нормализует повышенное окисление липидов, которое является процессом, сопровождающим многие заболевания внутренних органов и кожи.

Масла из зародышей пшеницы (МЗП) можно получить прессованием, углекислотной экстракцией, экстракцией органическими растворителями. Жирнокислотный состав МЗП представлен линолевой (44$63 \%)$, пальмитиновой (13-18\%), олеиновой (12-30\%), линоленовой (10-11\%), 9-октадеценовой (7-15\%). Масло зародышей пшеницы содержит большое количество минорных компонентов (каротиноиды, ситостерол, сквален, фолиевая кислота и др.), которые увеличивают его лечебные свойства [1-3].

В работе исследовали масла, полученные по щадящей технологии переработки зародышей пшеницы, разработанной профессором А.Б. Вишняковым [3, 4], для сравнения также проанализированы МЗП других производителей. Использовали кинетический метод микрокалориметрии [5, 6], который позволяет точно измерить количество токоферола-антиоксиданта в натуральных маслах [7-9].

\section{Материалы и методы}

Измерения проведены на микрокалориметре МКДП-2, произведенном в ИХН СО РАН по оригинальной конструкции [5]. Метод микрокалориметрии относится к кинетическим методам и основан на ре-

Сизова Наталия Витальевна - кандидат химических наук, научный сотрудник лаборатории физикохимических методов исследования, тел. (3822) 492-551; (3822) 507-359, e-mail: sizovaNV@mail.ru гистрации теплоты модельной реакции инициированного окисления кумола в присутствии ингибирующих добавок, методика описана в работах [810]. По периоду индукции реакции окисления кумо- 
ла можно оценить концентрацию антиоксидантов для сложных смесей природного происхождения, состав которых точно неизвестен. Работы по определению ингибитора-токоферола кинетическим методом известны, в работе [7] регистрация процесса окисления проводилась по поглощению кислорода, в нашем случае - по выделению тепла [5]. Ранее мы показали, что жирные масла тормозят радикальную реакцию с периодом индукции, пропорциональным содержанию токоферолов в масле [8]. В жирных маслах содержится большой набор соединений (например, каротиноиды, флавоноиды, фосфолипиды, жирные кислоты), которые могут проявлять себя как слабые ингибиторы окисления, и только токоферол относится к фенолам, которые способны тормозить реакции окисления с высокой константой скорости ингибирования: $\mathrm{k}_{7}=(1,4-6,8) \cdot 10^{4}$ л/моль·с [8]. Экспериментально определяемое содержание антиоксидантов пересчитывается на количество $\alpha$-токоферола, так как методика не позволяет выделить константу ингибирования для каждого гомолога. Поэтому в расчетах мы используем $\alpha$-токоферол как сильный ингибитор с одной функциональной группой $\mathrm{n}=1$, и стехиометрическим коэффициентом ингибирования $\mathrm{f}=2$.

Объекты исследования. В работе проанализированы образцы МЗП, выпущенные в разные годы, разными производителями, продающиеся через аптечные и продуктовые сети. Два образца капсулированы, остальные расфасованы во флаконы. Для девяти образцов МЗП, полученных в разных технологических циклах на предприятии «СибТар» (г. Новосибирск), также определены кислотность.

\section{Результаты и их обсуждение}

Количество токоферола может служить критерием качества масла и свидетельствовать о способе получения и качестве сырья [10]. Например, в образцах подсолнечных масел разных производителей содержание ТФ меняется от 60 до 90 мг\%. В кедровом масле нами на пяти образцах установлено содержание ТФ от 37 до 61 мг\%, и максимально это зависит от качества ореха, например, в январе 2014 г. два томских предприятия, получающих масло прессованием кедрового ореха, показали равное количество ТФ (3739 мг\%), что говорит об идентичном качестве исходного ореха урожая 2013 г. [11].

В таблице 1 приведены результаты измерений количества токоферола-антиоксиданта в маслах зародышей пшеницы, полученных разными производителями. Два образца масел содержат витамина $E$ в три раза меньше, чем приводится в справочной литературе (280-300 мг\%) [12]. Технические условия, разработанные на предприятии, могут допускать добавки к маслу зародышей пшеницы других масел, что должно указываться на этикетке в составе.

Мы проанализировали образцы МЗП, выпущенные в разные годы на предприятии ООО «СибТар» (г. Новосибирск), результаты приведены в таблице 2. Показано, что практически для всех образцов содержание витамина $E$ превышает справочные данные. Для образцов, полученных из разного сырья в разных технологических циклах, содержание токоферолов существенно отличается - до 150-170 мг\%. Наиболее низкое содержание витамина $E$ - у образца, произведенного в январе 2015 г. из зерна урожая 2014 г., что объясняется аномальными погодными условиями лета 2014 г. Образец №1 содержит максимальное количество токоферолов, на момент проведения измерений срок годности масла истек, но так как он был производен из высококачественного зерна, кислотность масла не превысила нормы.

Таблица 1. Сравнение данных по содержанию токоферолов в маслах зародышей пшеницы, (мг\% мг в 100 г). Ингибирующая активность масел измерена на модельной реакции окисление кумола (кислород, $\mathrm{t}=60^{\circ} \mathrm{C}$, Скорость инициирования $\mathrm{w}_{\mathrm{i}}=6,8 \times 10^{-8}$ моль/(л•с))

\begin{tabular}{l|c|c|c}
\multicolumn{1}{c|}{ Масло, производитель } & $\begin{array}{c}\text { Нормативные документы на производ- } \\
\text { ство масла }\end{array}$ & $\begin{array}{c}\text { [АО]·10-3, } \\
\text { моль/кг }\end{array}$ & $\begin{array}{c}\text { Содержание } \\
\text { ТФ, мг \% }\end{array}$ \\
\hline $\begin{array}{l}\text { «Масло зародышей пшеницы Вишнякова» } \\
\text { ООО «СибТар», Новосибирск (образцы раз- }\end{array}$ & ТУ 9141-009-50765127-0 7 & $8,21-9,84$ & $350-420$ \\
ныХ партий, произведены с 2011 по 2015 г.) & - & \\
ООО «Биаск», Москва & ТУ 9197-015-78056148-2010 & \\
ЗАО «РеалКапс», Московская область & ТУ 9141-018-42071416-2009 с изм №1. & 8,3 & $100-105$ \\
ЗАО «БиоКонтур», Владимирская область & СГР №RU.77.99.11.003.Е.004758.03.12 & 370 \\
& от 11.03.2012 г. & 360 \\
ООО «Аспера Лтд», Москва. Косметическое & ТУ 9158-004-99535663-07 с изм №1. & 2,7 & 116 \\
масло зародышей пшеницы с витаминно- & & 3,47 & 149 \\
антиоксидантным комплексом. Номер партии & & & \\
К8-10/1030 & & & \\
\hline
\end{tabular}




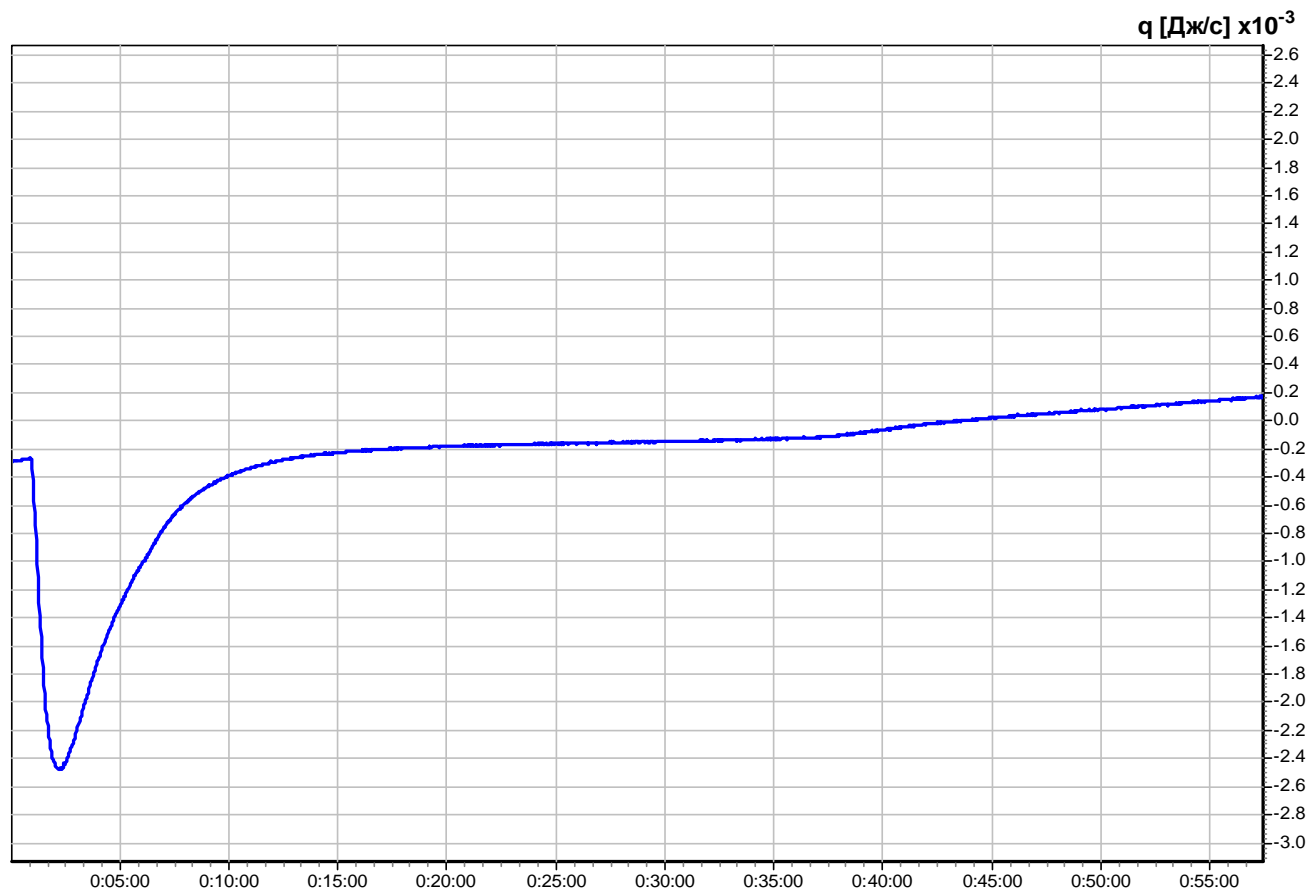

Кривые тепловыделения модельной реакции окисления кумола в присутствии масла зародышей пшеницы. С = 10,725 г/л, 4,4 мг АИБН, $60{ }^{\circ} \mathrm{C}$

В заводских лабораториях, следящих за качеством продуктов, методом определения свежести масла является измерение количества продуктов перекисного окисления - кислот и перекисей по государственному стандарту [13]. Для МЗП характерна несколько повышенная кислотность, для «салатного» масла, в составе которого 70\% подсолнечного масла, кислотность резко снижается. Максимальная кислотность установлена для образца №5, по причине использования зерна урожая предыдущего года (сырье хранилось в летний период), и вероятно, качество зерна ухудшилось. Как показали полученные нами результаты, нет связи между значениями кислотного числа и витамина $E$. Самое главное условие для получения высоковитаминного масла - качественное сырье.

Таким образом, выбирая МЗП как источник токоферолов, важно обратить внимание на дату изготовления и состав масла, в котором не должны значиться другие сорта масел.

Таблица 2. Содержание токоферолов в маслах зародышей пшеницы, полученных в разных технологических процессах. ООО «СибТар», г. Новосибирск

\begin{tabular}{|c|c|c|c|c|}
\hline № & Примечание, дата производства & $\begin{array}{c}\text { Кислотность, } \\
\text { мг КОН/г }\end{array}$ & $\begin{array}{c}\mathrm{AO}, 10^{-3}, \\
\text { моль/кг }\end{array}$ & $\begin{array}{l}\mathrm{T} \Phi, \\
\text { мГ\% }\end{array}$ \\
\hline 1 & Новосибирское производство, произведено 22.01.2009 г. & 6,8 & 9,8 & 423 \\
\hline 2 & Новосибирское производство, произведено 16.09.2011 г. & 7,6 & 9,4 & 402 \\
\hline 3 & Новосибирское производство, произведено 0.03.2008 г. & 7,0 & 8,6 & 369 \\
\hline 4 & Рубцовское производство, произведено 04.05.2011 г. & 3,4 & 8,2 & 354 \\
\hline 5 & Новосибирское производство, произведено 01.10.2011 г. & 12,1 & 8,8 & 377 \\
\hline 6 & Новосибирское производство, произведено 05.03.2011 г. & 4,8 & 8,7 & 372 \\
\hline 7 & Новосибирское производство, произведено 17.04.2011 г. & - & 7,9 & 347 \\
\hline 8 & Новосибирское производство, произведено 18.01.2015 г. & - & 5,6 & 238 \\
\hline 9 & Масло «салатное» (подсолнечное 70\%+МЗП 30\%), произведено 15.10.2011 г. & 0,3 & 2,7 & 117 \\
\hline
\end{tabular}

\section{Выводы}

Примененный в работе метод микрокалориметрии позволяет определить количество токоферолаантиоксиданта. Показано, что максимальное количество токоферолов содержится в масле зародышей пшеницы, полученном механической переработкой исходного сырья без нагревания и использования растворителей. Комплекс синергетических компонентов масла демонстрирует высокое содержание антиоксидантов, соответствующее количеству токоферолов от 250 до 420 мг\%. Для масел, полученных одним производителем 
в разных технологических циклах, содержание токоферолов существенно отличается, в зависимости от качества сырья и условий его хранения. Для двух образцов исследованных масел получены данные по содержанию витамина $E$ ниже справочных, что свидетельствует о разведении МЗП другим сортом масла.

Автор благодарит сотрудника предприятия ООО «СибТар» канд. биол. наук Е.А. Интересову за предоставление образиов и обсуждение результатов.

\section{Список литературы}

1. Шиков А.Н., Макаров В.Г., Рыженков В.Е. Растительные масла и масляные экстракты. Технология, стандартизация, свойства. М., 2004. 264 с.

2. Современные аспекты функционального питания. Клиническая эффективность масла зародышей пшеницы: методическое пособие для специалистов по питанию. Ч. 2 / под ред. Л.А. Шпагиной. Новосибирск, 2008.

3. Патент №2163922 (РФ). Способ извлечения масла и получения белкового продукта из низкомасличного растительного сырья, преимущественного из зародышей пшеницы / А.Б. Вишняков, В.Н. Власов, С.А. Грибовский, В.Н. Федосеев, Е.А. Интересова. 2001.

4. Вишняков А.Б., Власов В.Н., Спесивцев А.С., Жалнин В.Н., Пикус Б.И., Привалов В.А. Комплексная переработка зародышей пшеницы // Пищевая промышленность. 1996. №6. С. 50-52.

5. Патент № 224205 (РФ). Способ количественного определения токоферолов в растительных маслах / A.А. Великов, Н.В. Сизова. 2005.

6. А.с. №1437696 (СССР). Дифференциальный микрокалориметр / А.А. Великов, А.А. Вичутинский. 1988.

7. А.с. №761902 (СССР). Способ количественного определения ингибитора-токоферола в подсолнечном масле / Л.М. Радченко, В.Ф. Цепалов, М.Е. Кончаловская, А.А. Шмидт, В.И. Пастухова, З.Г. Козлова. 1980.

8. Сизова Н.В., Андреева Н.Ю. Определение витамина $E$ в растительных маслах методом микрокалоримтерии // Химико-фармацевтический журнал. 2007. №6. С. 49-52.

9. Сизова Н.В. Определение токоферолов, как липидных антиоксидантов в растительных маслах и животных жирах // Химия растительного сырья. 2013. №1. С. 157-163.

10. Sizova N.V. A Content of Tocopherols as a Criterion of Natural Fatty Oil Quality // Book of Abstracts 2 Annual Russian-Korean Conference «Current issues of natural products chemistry and biotechnology-2012». Novosibirsk, 2012. P. 150.

11. Сизова Н.В. Содержание антиоксидантов в редкоиспользуемых растительных маслах // Новые достижения в химии и химической технологии растительного сырья: материалы VI Всероссийской конференции. Барнаул, 2014. С. 433-436.

12. Витамины / под ред. В.В. Смирнова. М., 1974. С. 128.

13. ГОСТ 26593-85. Масла растительные. Метод измерения перекисного числа. М., 1994.

Поступило в редакичию 19 февраля 2015 г. 


\section{Sizova N.V. KINETIC DETERMINATION OF THE VITAMIN E CONTENT IN WHEAT GERM OILS}

Institute of Petroleum Chemistry SB RAS, pr. Academichesky, 4, Tomsk, 634055 (Russia), e-mail: sizovaNV@mail.ru

Using a calorimetric approach, the content of vitamin $\mathrm{E}$ in wheat germ oil produced by different manufacturers is determined. It is shown that the maximum amount of tocopherols is contained in the wheat germ oil produced by mechanical processing of the initial feedstock according to Prof. A.B. Vishnyakov's sparing technology. Eight samples of wheat germ oil produced in different processing cycles by the limited company 'SibTar' from 2011 to 2015 are analyzed. The synergistic oil components provide a high content in antioxidants, which accounts for the total content of tocopherols ranging from 240 to 420 $\mathrm{mg} \%$ and exceeds reference data. The main condition for obtaining oil with a high content of vitamins is the use of a high quality feedstock and pressing without heating or using any solvents. It is shown that the content of tocopherols for oils produced in different years varies by $40 \%$, depending most on the grain growth and its storage conditions. The content of tocopherols in a one kind of oil could serve as a quality criterion. Thus, the data on vitamin E content obtained for the two samples of tested wheat germ oils are three times lower than the reference data, which indicates that this oil was diluted with others kinds of oils.

Keywords: Wheat germ oil, natural antioxidants, kinetic method for determination of tocopherols.

\section{References}

1. Shikov A.N., Makarov V.G., Ryzhenkov V.E. Rastitel'nye masla i masljanye jekstrakty. Tehnologija, standartizacija, svojstva. [Vegetable oils and oil extracts. Technology, standardization, properties]. Moscow, 2004, 264 p. (in Russ.).

2. Sovremennye aspekty funkcional'nogo pitanija. Klinicheskaja jeffektivnost' Masla zarodyshej pshenicy: metodicheskoe posobie dlja specialistov po pitaniju. [Modern aspects of functional foods. Clinical efficacy of wheat germ oil: handbook for nutritionists], part 2, ed. L.A. Shpagina, Novosibirsk, 2008. (in Russ.).

3. Patent №2163922 (RU). 2001. (in Russ.).

4. Vishnjakov A.B., Vlasov V.N., Spesivcev A.S., Zhalnin V.N., Pikus B.I., Privalov V.A. Pishhevaja promyshlennost'. 1996, no. 6, pp. 50-52. (in Russ.).

5. Patent № 224205 (RU). 2005. (in Russ.).

6. Patent №1437696 (USSR). 1988. (in Russ.).

7. Patent №761902 (USSR). 1980. (in Russ.).

8. Sizova N.V., Andreeva N.Ju. Himiko-farmacevticheskij zhurnal, 2007, no. 6, pp. 49-52. (in Russ.).

9. Sizova N.V. Himija rastitel'nogo syr'ja, 2013, no. 1, pp. 157-163. (in Russ.).

10. Sizova N.V. Book of Abstracts 2 Annual Russian-Korean Conference "Current issues of natural products chemistry and biotechnology-2012”. Novosibirsk, 2012, p. 150.

11. Sizova N.V. Novye dostizhenija $v$ himii $i$ himicheskoj tehnologii rastitel'nogo syr'ja: materialy VI Vserossijskoj konferencii. [Advances in chemistry and chemical technology of vegetable raw materials: the VI All-Russian Conference]. Barnaul, 2014, pp. 433-436. (in Russ.).

12. Vitaminy. [Vitamins]. ed. Smirnov V.V. Moscow, 1974, 128 p. (in Russ.).

13. GOST 26593-85. Masla rastitel'nye. Metod izmerenija perekisnogo chisla. [State Standard 26593-85. Vegetable oils. The method of measuring peroxide value]. Moscow, 1994. (in Russ.). 
